\title{
Inhaled corticosteroids and adrenal insufficiency
}

\section{G Russell}

\section{Inhaled steroids are safe at normal doses, but beware very high doses, especially of fluticasone}

W hen inhaled corticosteroid therapy (ICT) was introduced to clinical practice thirty years ago, it appeared to be both effective and safe. ${ }^{2}$ There was no evidence of adrenal suppression at the recommended doses $^{34}$ and when oral corticosteroids were replaced by ICT, adrenal function recovered. ${ }^{56}$ It must be added that there were reports of adrenal atrophy on ICT, but these patients had also received oral corticosteroids, and it was generally thought unlikely that ICT was responsible.

Gradually, however, evidence began to appear that ICT did have systemic as well as topical effects, including dose-related adrenal suppression, ${ }^{8}$ although these biochemical phenomena did not appear to be associated with clinical symptoms. Clinicians generally felt that the advantages of ICT far outweighed the potential dangers, ${ }^{9}$ and not only did ICT gradually supplant sodium cromoglycate (cromolyn) as the first drug of choice for the prophylaxis of asthma, but over the years paediatricians began to follow their adult colleagues ${ }^{10}$ in prescribing greater than licensed doses of ICT. The use of such doses was not supported by the literature on ICT, which suggests a rather flat dose response curve for all types of ICT; even in studies in which the improvement on higher doses has been statistically significant, it has usually been so small as to be of little clinical importance. ${ }^{11-14}$ It must also be stated that the manufacturers have never advocated the use of such high doses of ICT.

Clinically, ICT did not have an entirely clean bill of health. There was the occasional report of adverse systemic effects in patients on ICT, ranging from oral candidiasis ${ }^{15}$ to overt cushingism ${ }^{16}$ and acute adrenal insufficiency both on ${ }^{17}$ and after discontinuing ICT. ${ }^{18}$ Dose related effects on growth generated a great deal of research activity, summarised by Wolthers, ${ }^{19}$ but clinicians were reassured by the finding of normal adult height despite prolonged ICT during childhood.$^{20}$ Despite these concerns, and constant admonition to step the dose of ICT down as well as up to establish the minimum effective dose, ${ }^{21} 22$ most clinicians have been complacent about the use of high-dose ICT.

This complacency was shattered with the publication of the three papers describing acute adrenal failure cited by Todd et al. These papers were multiauthor and multicentre and did not give the reader a feel for the frequency of this complication. This deficiency has now been remedied by Todd et al [see page 457], who in addition to showing that this problem is alarmingly common have also implicated fluticasone propionate (FP), the least frequently prescribed form of ICT, in the great majority of their cases. The association with FP might of course be spurious; clinicians, reassured by FP's excellent safety record, may have chosen FP as their drug of choice for patients requiring high dose ICT. However, given the prescribing data presented by Todd et al, such an explanation seems unlikely.

FP was originally developed as a drug apparently ideally suited for use by inhalation. The swallowed portion, representing the major part of the administered dose, ${ }^{23}$ is almost entirely destroyed on first pass hepatic metabolism, ${ }^{24}$ and the drug's high receptor affinity and prolonged dissociation half life $\mathrm{e}^{25}$ make it apparently ideal for use by intermittent inhalation. ${ }^{26}$ Early studies demonstrated the safety and efficacy of FP given to asthmatic children in doses of 100 to 200 $\mu \mathrm{g}$ per day, ${ }^{27}$ and numerous later studies confirmed these early impressions. ${ }^{28-33}$ Even at high doses, it was apparently no more toxic than beclomethasone. ${ }^{34}$

So what went wrong? In particular, has the pharmacology of FP been inadequately investigated? Hardly; a search of PubMed in August 2002 generated 795 papers on the pharmacology of FP and 208 on its adrenal effects. We know a great deal about FP, its pharmacology, and its effects on adrenal function.

FP is highly lipophylic, a prerequisite for a topically active corticosteroid, allowing it more easily to cross the cell membrane to attach itself to the glucocorticosteroid receptor. However, this feature also allows FP to cross easily into the circulation where its lipophilicity results in high tissue binding and a long half life. ${ }^{35}$ These features, combined with its high receptor affinity and prolonged duration of activity, ensure systemic potency and accumulation. ${ }^{36}$ From this information, it is easy to speculate that, at licensed doses, the hepatic destruction of the swallowed portion more than compensates for intrapulmonary absorption, accounting for FP's excellent safety profile. However, as the intrapulmonary dose increases, so does systemic absorption and hence systemic side effects such as adrenal suppression.

Other factors play a part in determining the systemic effects of ICT. Inhaler technique and compliance are clearly of major importance. Children frequently use holding chambers (spacers) that increase intrapulmonary deposition and efficacy $^{23} 37$ and will also enhance systemic absorption. The lung deposition of inhaled drugs increases with age, ${ }^{38}$ so the minimum effective dose may actually decrease as the child gets older. Systemic absorption is appreciably greater in normal volunteers than in asthmatic patients, ${ }^{39}$ which may explain why some non-asthmatics appeared in Todd's survey. Although as we have seen extrapolation is a dangerous pastime, it is reasonable to speculate that systemic absorption will increase as asthma comes under control, further emphasising the need to step doses down as well as up. It is however clear that the systemic dose of ICT bears only a passing resemblance to the administered dose, and will vary greatly between children and indeed in the same child from time to time. It is therefore impossible to state with certainty that one particular dose is safe while another is not. There is certainly no point in complicating the issue by expressing ICT doses in relation to weight or body surface area. What can be said with considerable certainty is that the optimum dose is the lowest effective dose, and that this dose will vary from time to time, and with the age of the child, the inhaler device used, and the degree of compliance.

What are the implications for the practising clinician? The findings of this survey cannot be ignored, but nor should they be used as an excuse for a further outbreak of steroid phobia. ${ }^{40}$ Nevertheless, there are implications both for patients already on high-dose FP, and for those for whom this therapy is contemplated.

Patients who are currently on high dose FP should remain on it, and they should be advised that this is a much safer option than suddenly discontinuing treatment. However, it would seem sensible to try to identify those few individuals in whom adrenal suppression has occurred by assessing adrenal function. My suggestion would be that children on FP in doses $\geqslant 1000 \mu \mathrm{g}$ per 
day should have a low dose short ACTH stimulation test, but the precise details of what should be done and to whom will depend on local practice and facilities.

For children who are not responding to conventional doses of ICT, and by this I think it is reasonable to imply doses up to twice the licensed doses, the clinician should address the following key questions.

Does the child have asthma? There has been excessive enthusiasm for the diagnosis of cough variant asthma, although ICT is superior to placebo for persistent cough in children. ${ }^{41}$ Archives has carried several papers on the difficulty parents experience in interpreting such terms as "wheeze" ${ }^{\text {"42 }}$ or "ruttles". ${ }^{43}$ Even when convincing wheeze is present, it is not necessarily asthmatic in origin, although it usually is, and clinicians must beware of missing such diagnoses as cystic fibrosis and bronchiectasis.

Are there avoidable trigger factors in the child's environment? Parents are often aware of these, but prefer the convenience of medication to the disruption of environmental control.

Are compliance and inhaler technique satisfactory? Compliance in asthma is notoriously poor, but can be improved by suitable educational input.

Has the use of non-steroidal alternatives been fully explored? This is the point at which to consider the introduction of a long-acting $\beta_{2}$ agonist, montelukast, or even low-dose theophylline.

\section{IS IT TIME TO CONSIDER REFERRAL TO A PAEDIATRIC RESPIROLOGIST?}

Finally, if high dose ICT is still considered necessary, I believe it is advisable for the time being to avoid the use of FP, which should nevertheless retain its place for use in conventional doses.

\section{Arch Dis Child 2002;87:455-456}

\section{Author's affiliation}

G Russell, Department of Medical Paediatrics, Royal Aberdeen Children's Hospital, Cornhill Road, Aberdeen AB25 2ZD, UK; libra@ifb.co.uk

\section{REFERENCES}

1 Brown HM, Storey G, George WH. Beclomethasone dipropionate: a new steroid aerosol for the treatment of allergic asthma. BM 1972; 1:585-590.

2 Field HV, Jenkinson PM, Frame MH, et al. Asthma treatment with a new corticosteroid aerosol, budesonide, administered twice daily by spacer inhaler. Arch Dis Child 1982;57:864-6
3 Harris DM, Martin LE, Harrison C, et al. The effect of oral and inhaled beclomethasone dipropionate on adrenal function. Clin Allergy 1973;3:243-8

4 Johansson SA, Andersson KE, Brattsand R, et al. Topical and systemic glucocorticoid potencies of budesonide and beclomethasone dipropionate in man. Eur J Clin Pharmacol 1982;22:523-9.

5 Bondarevsky E, Shapiro MS, Schey G, et al. Beclomethasone dipropionate use in chronic asthmatic patients. Effect on adrenal function after substitution for oral glucocorticosteroids. JAMA 1976;236:1969-71.

6 Harrison BD, Rees LH, Cayton RM, et al. Recovery of hypothalamo-pituitary-adrena function in asthmatics whose oral steroids have been stopped or reduced. Clin Endocrinol (Oxf) 1982;17:109-18.

7 Mellis CM, Phelan PD. Asthma deaths in children - a continuing problem. Thorax 1977;32:29-34.

8 Law CM, Marchant JL, Honour JW, et al. Nocturnal adrenal suppression in asthmatic children taking inhaled beclomethasone dipropionate. Lancet 1986;1:942-4.

9 Brown HM. Nocturnal adrenal suppression in children inhaling beclomethasone dipropionate. Lancet 1986;1:1269.

10 Smith MJ, Hodson ME. High-dose beclomethasone inhaler in the treatment of asthma. Lancet 1983;1:265-9.

11 Gaddie J, Petrie GR, Reid IW, et al. Aerosol beclomethasone dipropionate: a dose-response study in chronic bronchial asthma. Lancet 1973;2:280-1.

12 Pedersen S, Hansen OR. Budesonide treatment of moderate and severe asthma in children: a dose- response study. J Allergy Clin Immunol 1995;95:29-33.

13 Katz Y, Lebas FX, Medley HV, et al. Fluticasone propionate 50 micrograms BID versus 100 micrograms BID in the treatment of children with persistent asthma. Fluticasone Propionate Study Group. Clin Ther 1998;20:424-37

14 Bousquet J, Ben Joseph R, Messonnier M, et al. A meta-analysis of the dose-response relationship of inhaled corticosteroids in adolescents and adults with mild to moderate persistent asthma. Clin Ther 2002;24:1-20.

15 Shaw NJ, Edmunds AT. Inhaled beclomethasone and oral candidiasis. Arch Dis Child 1986;61:788-90.

16 Hollman GA, Allen DB. Overt glucocorticoid excess due to inhaled corticosteroid therapy. Pediatrics 1988:81:452-5.

17 Zimmerman B, Gold M, Wherrett D, et al. Adrenal suppression in two patients with asthma treated with low doses of the inhaled steroid fluticasone propionate. J Allergy Clin Immunol 1998;101:425-6.

18 Zwaan CM, Odink R, Delemarre-van de Waal HA, et al. Acute adrenal insufficiency after discontinuation of inhaled corticosteroid therapy. Lancet 1992;340: 1289-90.

19 Wolthers OD. Long-, intermediate- and short-term growth studies in asthmatic children treated with inhaled glucocorticosteroids. Eur Respir J 1996:9:821-7.

20 Agertoft L, Pedersen S. Effect of long-term treatment with inhaled budesonide on adult height in children with asthma. N Engl J Med 2000;343:1064-9.

21 Guidelines on the management of asthma. Thorax 1993;48:S1-24.

22 The British Guidelines on Asthmo Management-1995 review and position statement. Thorax 1995;52(Suppl I):S1-20.

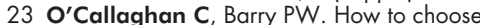
delivery devices for asthma. Arch Dis Child 2000;82: 185-7.

24 Falcoz C, Oliver R, McDowall JE, et al. Bioavailability of orally administered micronised fluticasone propionate. Clin Pharmacokinet 2000;39(Suppl 1):9-15.

25 Hogger P, Rohdewald P. Binding kinetics of fluticasone propionate to the human glucocorticoid receptor. Steroids 1994;59:597-602.

26 Fuller $\mathbf{R}$, Johnson $M$, Bye A. Fluticasone propionate - an update on preclinical and clinical experience. Respir Med 1995;89(Suppl A):3-18.

27 Russell G. Fluticasone propionate in children. Respir Med 1994:88(Suppl A):25-29.

28 Kannisto S, Korppi M, Remes K et al. Adrenal suppression, evaluated by a low dose adrenocorticotropin test, and growth in asthmatic children treated with inhaled steroids. J Clin Endocrinol Metab 2000;85:652-7.

29 ZuWallack R, Adelglass J, Clifford DP, et al. Long-term efficacy and safety of fluticasone propionate powder administered once or twice daily via inhaler to patients with moderate asthma. Chest 2000;1 18:303-12.

30 Ferguson AC, Spier S, Manjra A, et al. Efficacy and safety of high-dose inhaled steroids in children with asthma: a comparison of fluticasone propionate with budesonide. J Pediatr 1999;134:422-7

31 Rao R, Gregson RK, Jones AC, et al. Systemic effects of inhaled corticosteroids on growth and bone turnover in childhood asthma: a comparison of fluticasone with beclomethasone. Eur Respir J 1999;13:87-94.

32 Allen DB, Bronsky EA, LaForce CF, et al. Growth in asthmatic children treated with fluticasone propionate. J Pediatr 1998;132:472-7.

33 Price JF, Russell G, Hindmarsh PC, et al Growth during one year of treatment with fluticasone propionate or sodium cromoglycate in children with asthma. Pediatr Pulmonol 1997;24:178-86.

34 Fitzgerald D, Van Asperen P, Mellis C, et al. Fluticasone propionate 750 micrograms/day versus beclomethasone dipropionate 1500 micrograms/day: comparison of efficacy and adrenal function in paediatric asthma. Thorax 1998;53:656-61.

35 Mackie AE, Ventresca GP, Fuller RW, et al. Pharmacokinetics of intravenous fluticasone propionate in healthy subjects. Br J Clin Pharmacol 1996;41:539-42.

36 Lipworth BJ. Systemic adverse effects of inhaled corticosteroid therapy: A systematic review and meta-analysis. Arch Intern Med 1999; 159:941-55.

37 Everard ML. Guidelines for devices and choices. J Aerosol Med 2001;14/Suppl 1):S59-S64

38 Onhoj J, Thorsson L, Bisgaard H. Lung deposition of inhaled drugs increases with age. Am J Respir Crit Care Med 2000;162:1819-22.

39 Brutsche $\mathbf{M H}$, Brutsche IC, Munawar M, et al. Comparison of pharmacokinetics and systemic effects of inhaled fluticasone propionate in patients with asthma and healthy volunteers: a randomised crossover study. Lancet 2000;356:556-61.

40 Patterson R, Walker CL, Greenberger PA, et al. Prednisonephobia. Allergy Proc 1989:10:423-8

41 Davies MJ, Fuller P, Picciotto A, et al. Persistent nocturnal cough: randomised controlled trial of high dose inhaled corticosteroid. Arch Dis Child 1999;81:38-44

42 Cane RS, McKenzie SA. Parents interpretations of children's respiratory symptoms on video. Arch Dis Child 2001;84:31-4.

43 Elphick HE, Sherlock P, Foxall G, et al. Survey of respiratory sounds in infants. Arch Dis Child 2001:84:35-9. 